\title{
Ueber den Bau der rothen Blättchen an den Schwingen des Seidenschwanzes.
}

Von

\section{Dr. Ludwig Stieda,}

Prorector und ausserordentlichem Professor in Dorpat.

Hierzu ein Holzschnitt.

Bekanntlich zeigen die Schwungfedern zweiter Ordnung (Armschwingen) des Seidenschwanzes (Ampelis garrula K. oder Bombicilla garrula) an ihrem äussersten Ende ein kleines scharlachrothes oder korkrothes Blättchen. Dasselbe ist annähernd spatelförmig gestaltet und erscheint als unmittelbare Fortsetzung des Federschafts, speciell des sogen. Dornfortsatzes (Heusinger). Bei genauer Betrachtung ist zu erkennen, dass die vom Körper abgewandte Fläche (nach Heusinger die äussere Fläche) des Blättchens convex und lebhaft glänzend roth erscheint, während die dem Körper zugekehrte Fläche (innere Fläche) eben und matter gefärbt ist.

Die beschriebenen Endblättchen scheinen niemals mikroskopisch untersucht worden zu sein; wenigstens finde ich nirgends eine Notiz darüber, obgleich selbstverständlich in den geläufigen Handbüchern der Zoologie von ihnen die Rede ist. Ich weiss nur zwei Aufzeichnungen anzuführen, in denen etwas mehr von den Blättchen gesprochen wird, als in den Handbüchern der Zoologie. Heusing er (System der Histologie, I. Theil Histographie, Eisenach 1822, p. 212) versucht eine Erklärung und Deutung der Endblättchen zu geben; bei Beschreibung der Federfahne sagt er, dass bei vielen Fahnen die Strahlen sehr nahe stehen, dass die Nebenstrahlen zahnförmig in einander greifen und dadurch die Fahne fast zu einem Stuick werde. Weiter heisst es dann: „Dieses Aneinanderdrängen der Strahlen kann endlich so weit gehen, dass sie ganz mit einan- 
der verwachsen und so die schuppenförmigen Federn bilden, die vorzüglich ausgebildet auf den Flügeln der Pinguine vorkommen. Aehnlich sind die rothen schuppenförmigen Spitzen auf einigen Flügelfedern des Seidens $\mathrm{chwazzes}$, an den Halsfedern des Sonnerat'schen Hahns und der Columba Franoix u. s. w. In allen diesen Federn scheint die Hornsubstanz des Dornfortsatzes und der Strahlen mit einander zu verschmelzen, um diese hornartigen durchscheinenden Schüppchen oder Blättchen zu bilden." Es wird sich in der Folge herausstellen, dass die Ansicht Heusinger's nicht richtig ist.

Eine andere wohl ältere Auffassung, deren ursprüngliche Quelle ich nicht kenne, führt Leydig an (Lehrbuch der Histologie, 1857, p. 99 in der Anmerkung): „Die eigenthümlichen scharlachrothen Blättchen am Ende der 5-7 hinteren Schwanzfedern des Seidenschwanzes dürften auch näher untersucht werden. Nach älteren Mittheilungen wären sie keine Fortsetzung der Federn, sondern nur „Anhängsel aus einer bröckeligen Materie, wie Lack" u.s. w."

Die Federn des Seidenschwanzes haben - abgesehen von ihrer Färbung und den genannten rothen Endblättchen - nichts besonderes. Ich übergehe daher hier das, was den Bau der Feder im Allgemeinen betrifft, indem ich in nächster Zeit eine ausführliche Abhandlung über Bau und Entwickelung der Federn veröffentlichen werde, und verweise auf eine vorläufige Mittheilung über denselben Gegenstand in der St. Petersburger Medic. Zeitschrift Bd. XVII, 1869 (Ueber Bau und Entwickelung der Federn. Ein Vortrag).

Um den Bau der Endblättchen zu erforschen, schlug ich nach einigen vergeblichen Versuchen folgenden Weg ein.

Ich fertigte feine Querschnitte der Endblättchen an, welche ich nach Zusatz von Kreosot mikroskopisch untersuchte. An solch einem Querschnitt liess sich bei schwacher Vergrösserung eine helle Rinde und eine dunkle Marksubstanz (cf. Fig. 1) erkennen. Die

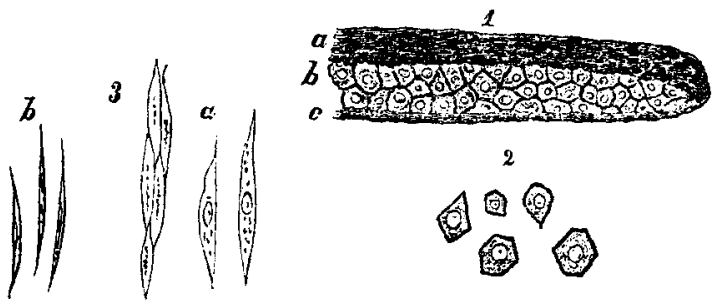


Rindenschicht war an der convexen Fläche mächtiger, als an der geraden. Bei stärkerer Vergrösserung erwies sich die undurchsichtige Marksubstanz als durchweg lufthaltig; durch das Kreosot wurde allmählig die hier fin Zellen eingeschlossene Luft verdrängt. War endlich alle Luft vertrieben, so erschien die Marksubstanz heller als die Rinde und zusanmengesetzt aus polyedrischen Zallen. Die Zellen der Marksubstanz waren ungefärbt oder enthielten nur Spuren eines feinkörnigen rothen oder gelben Pigments. Die Rindensubstanz war mehr oder weniger homoggen, durchsichtig; und enthielt einen diffusen röthlichen Farbstoff; Zellenconturen waren gar nicht oder nur so undeutlich zu erkennen, lass über die eigentliche Form derselben nichts ausgesagt werden konnte. Suhon nach diesem Befund allein kann man behaupten, dass die Endblättchen genau den Bau des Feder'schaftes haben. Es liam darauf an, dies durch nähere Untersuchung resp. Isolirung der Zellen näher zu bestimmen, und hierzu eignet sich unter allen Reagentien keines besser, als die concentrirte Schwefelsäure. lch verfuhr dabei folgendermassen: Ich brachte ein rothes Endblättchen auf einen Objectträiger, träufelte etwas Schwefelsäure darauf und bedeckte es mit einem Deckgläschen, dann erwärmte ich den Objectträger ganz gelinde über einer Spiritusflumme. Die erste Veränderung war eine ziemlich schnell eintretende Entfärbung des Endblättchens; die darauf folgende, wie zu erwarten, ein Zerfall des Blättchens in die dasselbe zusammensetzenden zelligen Elemente. Die Rindensubstanz (Fig. 3) setzte sich zusammen aus langgestreckten, rhombischen oder spindelförmigen platten Zellen; ein Kern war nicht immer wahrnehmbar, nur an einzelnen Zellen. Die Zellen waren 0,07.1 Nm. lang, 0,011 $\mathrm{Mm}$. breit und etwa 0,004-0,005 Mm. dick. Die Rindenzellen waren so angeordnet, dass der Längsdurchmesser der Zelle mit der Längsaxe der Feder zusammenfiel und die Zellen mit ihrer breiten Fläche der breiten Federfläche sich anschlossen. Die Zellen der Rindensubstanz sind eng aneinander gefügt und durch den Verhornungsprozess derartig verändert, dass an gewöhnlichen Querschnitten der Blättchen eine Zusammensetzung aus Zellen kaum zu erkennen ist; meist ist die Rinde homogen, hier wieder etwas gefleckt und selten einige Zellenconturen sichtbar.

Die Marksubstanz (Fig. 2) zerfiel beim Kochen mit Schwefelsäure in polyedrische aber sehr unregelmässig gestaltete Zellen. Dass die Zellen nicht polygonale Platten, sondern polyedrische Kör- 
perchen sind, lässt sich zum Theil durch die Ergebnisse verschiedener Schnittrichtungen, zum Theil auch durch die Beobachtung derjenigen isolirten Zellen, welche durch Strömungen unter dem Deckglase bewegt werden, darthun. Der Durchmesser der Zellen beträgt etwa 0,0143-0,0171 Mm. Alle Zellen der Marksubstanz sind lufthaltig; die Membran der Zelle schliesst ein einziges der Grösse der Zelle entsprechendes Luftbläschen ein. Ist durch Kochen mit Schwefelsäure die Luft entfernt, so erscheint in jeder Zelle ein runder Kern, 0,008 Mm. im Durchmesser; übrigens werden die Kerne auch an Schnitten, welche einfach mit Kreosot behandelt worden sind, sichtbar.

Zum Vergleich behandelte ich einen Querschnitt aus dem untern Theil eines Federschaftes in gleicher Weise mit Schwefelsäure: das Resultat war dasselbe. Es zerfiel die Rindensubstanz in platte, langgestreckte Zellen, die Marksubstanz in polyedrische.

Das Resultat meiner Untersuchung ist: „Das s charlachrothe Blättchen anden Schwingeudes Seidenschwanzes ist das abgeflachte Ende des Federschaftes und besteht deshalb wie der Schaft aus einer Marksubstanz und einer Rindensubstanz.

Dorpat im März 1872.

\section{Erklärung der Figuren.}

1. Ein durch Kreosot aufgehellter Querschnitt des Endblättchens. a stark und schwach gefärbte Rindensubstanz, b Marksubstanz.

2. Zellen der Marksubstanz durch Kochen mit $\mathrm{SO}_{3}$ isolirt.

3. Zellen der Rindensubstanz dureh Kochen mit $\mathrm{SO}_{3}$ isolirt. a von der Fläche gesehen, b von der Kante gesehen. 